Article

\title{
Photosynthetic Accumulation of Lutein in Auxenochlorella protothecoides after Heterotrophic Growth
}

\author{
Yibo Xiao ${ }^{1}$, Xi He ${ }^{1}$, Qi Ma ${ }^{2}$, Yue $\mathrm{Lu}^{3}$, Fan Bai ${ }^{2}$, Junbiao Dai ${ }^{1,4, *}$ and Qingyu Wu ${ }^{1, *}$ \\ 1 Key Laboratory of Industrial Biocatalysis (Ministry of Education) and Center for Synthetic and Systems \\ Biology, School of Life Sciences, Tsinghua University, Beijing 100084, China; \\ xiaoyb14@mails.tsinghua.edu.cn (Y.X.); hexi_1990@163.com (X.H.) \\ 2 Biodynamic Optical Imaging Center (BIOPIC), School of Life Sciences, Peking University, Beijing 100871, \\ China; maqi@pku.edu.cn (Q.M.); fbai@pku.edu.cn (F.B.) \\ 3 School of Food and Biological Engineering, Xihua University, Chengdu 610039, China; \\ luyue2017@mail.xhu.edu.cn \\ 4 Center for Synthetic Biology Engineering Research, Shenzhen Institutes of Advanced Technology, \\ Chinese Academy of Sciences, Shenzhen 518055, China \\ * Correspondence: junbiao.dai@siat.ac.cn (J.D.); qingyu@tsinghua.edu.cn (Q.W.); \\ Tel./Fax: +86-755-86585244 (J.D.); +86-10-62781825 (Q.W.)
}

Received: 18 July 2018; Accepted: 14 August 2018; Published: 16 August 2018

\begin{abstract}
In order to enhance lutein accumulation and to explain the reasons for the difference in lutein accumulation under photoautotrophic and heterotrophic conditions, different culture modes and the associated transcriptome profiles were investigated in Auxenochlorella protothecoides. The heterotrophic-photoautotrophic transition culture mode was investigated for lutein accumulation, changing from organic carbon to increase biomass in dark fermentation to irradiation under nitrogen rich conditions. This strategy increased the lutein content 10 times along with chloroplast regeneration and little biomass loss in $48 \mathrm{~h}$. The highest lutein productivity and production in the heterotrophic-photoautotrophic transition culture reached $12.36 \mathrm{mg} / \mathrm{L} /$ day and $34.13 \mathrm{mg} / \mathrm{L}$ respectively within seven days. Furthermore, compared to the photoautotrophic conditions, most genes involved in lutein biosynthesis and photosystem generation were down-regulated during heterotrophic growth. By contrast, two $\beta$-ring hydroxylases were transiently upregulated, while violaxanthin de-epoxidase and zeaxanthin epoxidase were mostly downregulated, which explained the extremely low lutein content of heterotrophic cells. Nevertheless, the lutein proportion in total carotenoids reached nearly $100 \%$. This study is the first to our knowledge to report on a comparative transcriptome analysis of lutein biosynthesis, and it provides a promising strategy to boost lutein production in $A$. protothecoides.
\end{abstract}

Keywords: microalgae; lutein; two-stage cultivation; heterotrophic-photoautotrophic transition; comparative transcriptomics

\section{Introduction}

Carotenoids, which contain a large conjugated double-bond system, play a key role in plant and microalgal photosynthesis and photoprotection [1]. Moreover, their use as effective preventive agents against a variety of human diseases has also been proposed [2-5]. Lutein is the second most valuable pigment belonging to the xanthophyll family, and it has gained increasing attention due to its wide range of applications, including prevention of acute and chronic coronary syndrome, as well as stroke, retinitis, and age-associated macular degeneration, while also helping to maintain normal 
visual function and avoiding gastric infection by Helicobacter pylori. Moreover, it has antioxidant properties and anti-cancer activity [6-13]. Conventionally, lutein is extracted from marigold flowers, which requires a labor-intensive harvesting process but yields a low lutein content (about 0.03\%) [14]. Thus, an alternative commercial source of lutein is urgently needed.

Recently, microalgae have become attractive sources of valuable metabolites due to their ability to sequester carbon dioxide and to synthesize nutritional antioxidants, such as polyunsaturated fatty acids and natural pigments. These diverse components can be utilized in different fields such as adjuvant drugs [15], dietary supplements [16], seafood baits [17], and cosmetics [18]. Compared with marigold flowers, microalgae are much more intensive sources of lutein, with a 5-10 times higher growth rate, no competition for land resources with conventional agriculture, and the possibility of year-round harvest [14]. Many strains of microalgae such as Chlorella sp., Coelastrella sp., Parachlorella kessleri, and Scenedesmus bijugatus, can naturally accumulate non-negligible amounts of lutein, ranging from 0.28 to $6.49 \mathrm{mg} / \mathrm{g}$ [19]. However, their lutein productivity and titers are unacceptably low due to slow phototrophic growth and consequently poor biomass accumulation.

The current productivity of microalgal biomass in photoautotrophic cultivation range from 0.055 to $0.061 \mathrm{~g} / \mathrm{L} /$ day at the laboratory scale and is much lower at the industrial scale, and therefore cannot meet the demands of the global lutein market [20]. Although heterotrophic fermentation can dramatically enhance the algal biomass productivity and provide large amounts of protein or oil resources [15], the low content of pigments greatly limits the economics of lutein extraction and results in a severe bottleneck for its commercial production in microalgae. A. protothecoides as an efficient lutein-production alga has high potential for application in the commercial production of lutein; meanwhile A. protothecoides has high lipid content (about $60 \%$ ) by heterotrophic fermentation system, offering a feasible pathway to produce oil feedstock for microbio-diesel production in a large scale [21,22]. A. protothecoides is a facultatively heterotrophic microalga with two growth modes that can be interconverted by controlling the culture conditions. It can be grown either photoautotrophically with a sufficient nitrogen source or heterotrophically by using glucose as a carbon source under dark-fermentation conditions. Moreover, it can be switched from autotrophy to heterotrophy and converted back again through specific stress conditions, leading to the accumulation of specific secondary metabolites, including carotenoids. Previous studies already used two-stage cultivation processes for the production of fucoxanthin in the marine diatom Nitzschia laevis, as well as lutein in Chlorella sorokiniana MB-1 and Chlorella sorokiniana MB-1-M12 [23-25]. As a result, we can boost the lutein content by controlling the culture condition to manipulate the metabolic process of A. protothecoides.

The different patterns of carotenoid accumulation between photoautotrophic and heterotrophic cells are well known, and there is a large body of research on the metabolic pathways of carotenoids in higher plants and microalgae $[22,26,27]$. However, there are only few studies on the differences in the molecular mechanisms of lutein accumulation under different culture conditions in microalgae. Transcriptomics is a powerful tool that can reveal the mechanisms of metabolic regulation at the genetic level [28]. The transcriptomic study of metabolic pathways is a good way to understand the differences of lutein accumulation in autotrophic and heterotrophic cells, and can provide a theoretical basis for further genetic engineering of industrial strains to increase their lutein content in the future.

In this study, to achieve highly efficient lutein production in A. protothecoides, we employed a dual-culture strategy comprising heterotrophic growth for biomass accumulation followed by photoautotrophic cultivation. The effects of different nitrogen sources on lutein accumulation, and the relationship between lutein accumulation and chloroplast regeneration were studied. Furthermore, to understand the reasons for the difference of lutein accumulation under photoautotrophic and heterotrophic conditions, the differences in the expression of genes related to lutein biosynthesis between heterotrophic and photoautotrophic cells, as well as the genes encoding components of the photosystem were analyzed in detail at the transcriptional level for the first time. 


\section{Results and Discussion}

\subsection{Lutein Lccumulation in Different Culture Modes}

In contrast to most microalgae, $A$. protothecoides can utilize large amounts of glucose for heterotrophic growth, and it can switch its metabolic pattern rapidly after the culture conditions are changed. Five culture modes were studied for the accumulation of biomass, lutein and total carotenoids (Figure 1), including one-stage culture modes (AC: photoautotrophic cultivation, MC: mixotrophic cultivation, HC: heterotrophic cultivation) and two-stages culture modes (HM: heterotrophic-mixotrophic cultivation, HA: heterotrophic-photoautotrophic cultivation).

When evaluating or optimizing the production of a particular metabolite by microalgal cultures, biomass and the relative content of the target compound are the two most relevant parameters that have to be considered [29]. Among the one-stage culture modes, HC yielded a much higher biomass than AC. HM produced an especially highest biomass, which can be explained by the addition of $30 \mathrm{~g} / \mathrm{L}$ glucose in the second stage (Figure 1a). The contents of lutein and total carotenoids were 5.35 and $2.69 \mathrm{mg} / \mathrm{g}$ in $\mathrm{AC}$, respectively, which was significantly higher than that of either MC or $\mathrm{HC}(p<0.05)$ (Figure 1b). By contrast, the same contents in HA were 6.23 and $3.32 \mathrm{mg} / \mathrm{g}$, respectively, the highest among the five culture modes. MC and HM left residual glucose in the later period of the cultures, which prevented the cells from accumulating lutein after switching to fresh photoautotrophic medium, and this inhibitory effect increased as the glucose concentration increased within $24 \mathrm{~h}$ (Figure S1).

Lutein production was much higher in the two-stage than the one-stage culture modes, whereby HA and HM yielded 19.65 and $21.04 \mathrm{mg} / \mathrm{L}$, respectively (Figure 1c). The lutein production of HM was slightly higher than that of HA because of the higher biomass yield of the former. However, the lutein content of HM was 49.8\% lower than HA. Moreover, the second stage of HM consumed additional glucose. In order to evaluate lutein production, the lutein content was more important than the biomass. Accordingly, HA was the most suitable culture mode for lutein production.

\subsection{Lutein Accumulation in the Heterotrophy-Photoautotrophy Culture Mode}

Low level of nitrogen prompted $A$. protothecoides to use glucose for heterotrophic growth, and high level of nitrogen prompted $A$. protothecoides to synthesis chloroplast and photosynthetic pigments for photoautotrophic growth. In the heterotrophic-photoautotrophic approach, A. protothecoides was firstly grown heterotrophically under nitrogen starvation, and then transferred into photoautotrophic medium containing replete nitrogen to induce carotenoids accumulation. In previous work, the biomass of heterotrophic cultures reached as high as $100.5 \mathrm{~g} / \mathrm{L}$ [21]. Hence, this study focused on the photoautotrophic stage of HA. Light intensity was suggested as a key factor that affected biomass and the carotenoids production of microalgae [3]. During photoautotrophic cultivation, appropriate nutrients and optimal light intensity at their optimal levels would increase the accumulation of lutein. However, light intensity had a smaller contribution to lutein accumulation than nutrients in the photoautotrophic stage of $A$. protothecoides (data not shown). Abundant nitrogen source is the key nutrient to photoautotrophic growth of $A$. protothecoides [30]. Three nitrogen sources-urea, $\mathrm{NH}_{4} \mathrm{Cl}$, and glycine, were used for lutein accumulation after heterotrophic growth. Figure 2 shows the time-course profiles of biomass, proportion of lutein in total carotenoids, content of lutein and total carotenoids, and production and productivity during the photoautotrophic stage of HA. 

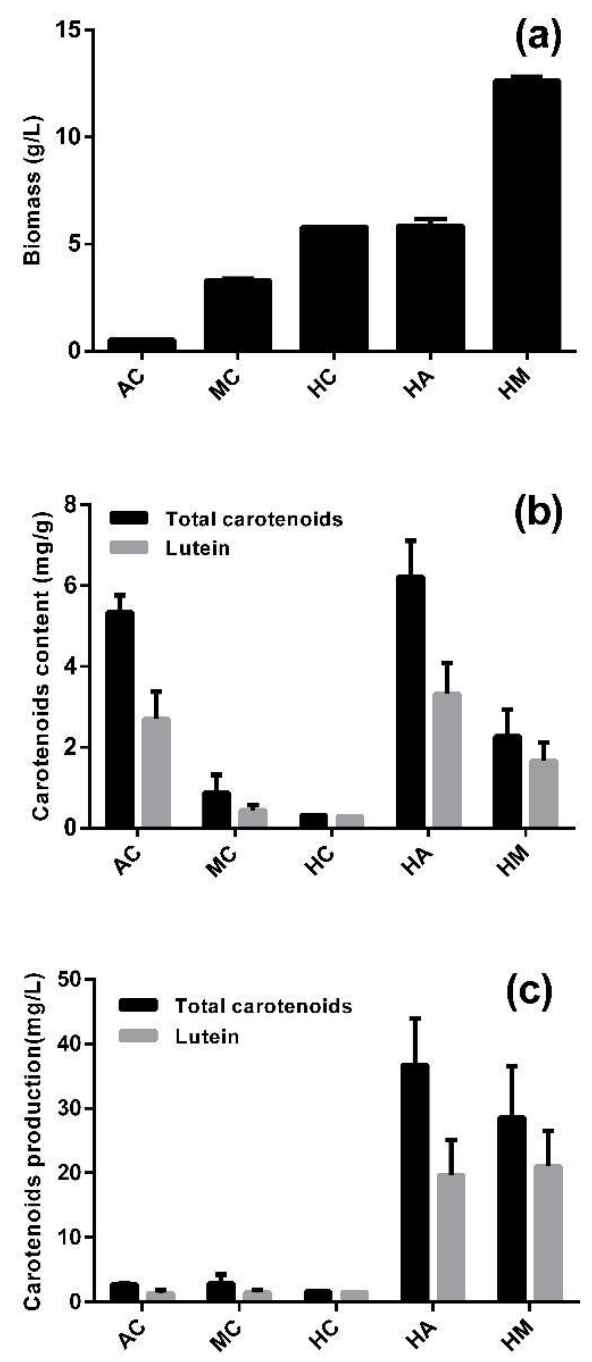

Figure 1. The accumulation of carotenoids by A. protothecoides in different culture modes. (a) Biomass accumulation in different culture modes; (b) content of lutein and total carotenoids in different culture modes; (c) the production of lutein and total carotenoids in different culture modes.

After five days in the photoautotrophic stage, the biomass increased by 0.67 and $1.03 \mathrm{~g} / \mathrm{L}$ with urea and glycine, respectively, while it decreased by $0.17 \mathrm{~g} / \mathrm{L}$ with $\mathrm{NH}_{4} \mathrm{Cl}$ (Figure 2a). This demonstrated that the large amount of heterotrophically grown cells transitioned to photoautotrophic conditions and were still active. It was found that the contents of lutein and total carotenoids increased quickly during the first two days on urea and glycine, but $\mathrm{NH}_{4} \mathrm{Cl}$ was not a suitable nitrogen source for carotenoid accumulation (Figure 2a,f). This implies that organic nitrogen sources could more easily be used by A. protothecoides than inorganic nitrogen. The maximum lutein content reached 4.92 and $4.99 \mathrm{mg} / \mathrm{g}$ on urea and glycine on the fifth day. Although the heterotrophic cells were almost completely devoid of carotenoids, with total carotenoids contents of $0.27,0.32$ and $0.25 \mathrm{mg} / \mathrm{g}$ on urea, $\mathrm{NH}_{4} \mathrm{Cl}$ and glycine, respectively, lutein accounted for almost all of the total carotenoids. Moreover, in the next few days the proportion of lutein in total carotenoids remained at about $60 \%$ with all three nitrogen sources (Figure 2e). This means that lutein remained the major carotenoid in A. protothecoides in all the different culture periods. The highest lutein production reached 26.72 and $34.13 \mathrm{mg} / \mathrm{L}$ with urea and glycine (Figure 2c), and total carotenoids reached 39.12 and $49.20 \mathrm{mg} / \mathrm{L}$ (Figure 2g), respectively. Therefore, urea and glycine as nitrogen source were suitable for lutein production. Productivity is another parameter for evaluating the lutein production ability. As shown in Figure 2d,h, the productivity of lutein and total carotenoids with the three nitrogen sources first increased, and later decreased. In the 
photoautotrophic stage, the highest lutein productivity reached $12.36 \mathrm{mg} / \mathrm{L} /$ day with glycine on the second days, which was higher than most reported so far [31]. Hence, glycine is most suitable nitrogen source for lutein production in A. protothecoides.
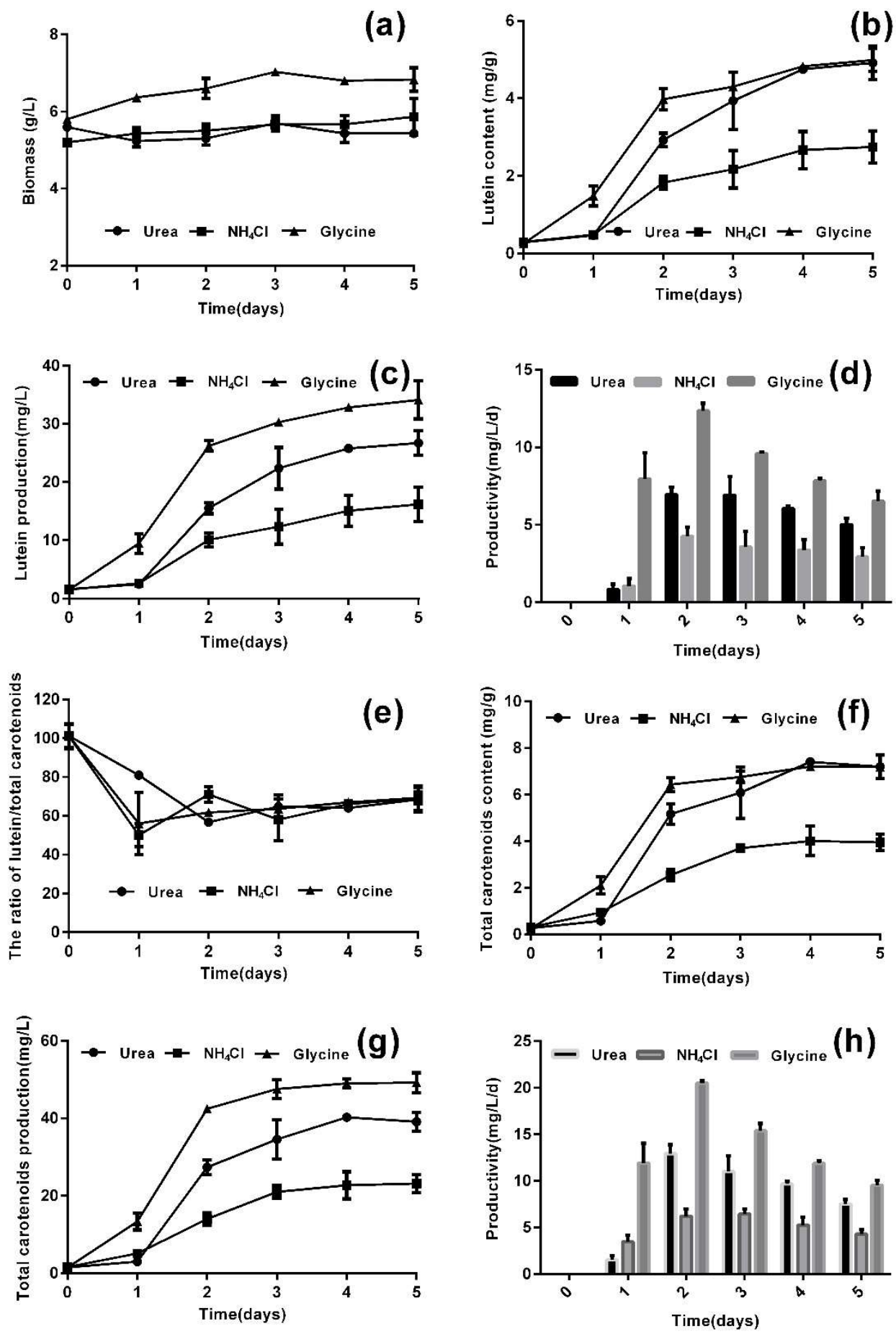

Figure 2. Accumulation of carotenoids in heterotrophic-photoautotrophic (HA) transition culture mode with three nitrogen sources. The time course profiles of (a) biomass, (b) lutein content, (c) lutein production, and (d) lutein productivity after the HA transition; (e) the proportion of lutein in total carotenoids; (f) the time course profiles of the total carotenoid content; (g) the time course profiles of total carotenoids production; (h) total carotenoid productivity after the HA transition. 


\subsection{Lutein Biosynthesis and Chloroplast Regeneration under Nitrogen-Replete Conditions}

The lutein content increased over time during the photoautotrophic stage, and the color of the A. protothecoides cells changed from yellow to light, and later dark green. Yellow cells are filled with lipid droplets and contain almost no chloroplasts [32], while green cells have few lipid droplets but are filled with chloroplasts. Hence, the process of the heterotrophy-photoautotrophy transition is accompanied by chloroplast regeneration. Chlorophyll fluorescence was almost non-existent in the heterotrophic cells and gradually increased with time during the photoautotrophic stage, which indicated the regeneration of chloroplasts (Figure 3). In the heterotrophic stage, because of the lack of photosynthesis and chloroplasts, A. protothecoides could not accumulate significant amounts of lutein. We previously found that the presence of glucose inhibits the accumulation of lutein under lights even in the presence of ample nitrogen source (Figure S1). It is possible that the presence of glucose inhibits photosynthesis and chloroplast development in A. protothecoides. Lutein is a pigment used for photosynthesis and photoprotection, which implies that lutein accumulation is most likely associated with chloroplast regeneration and photosynthesis.

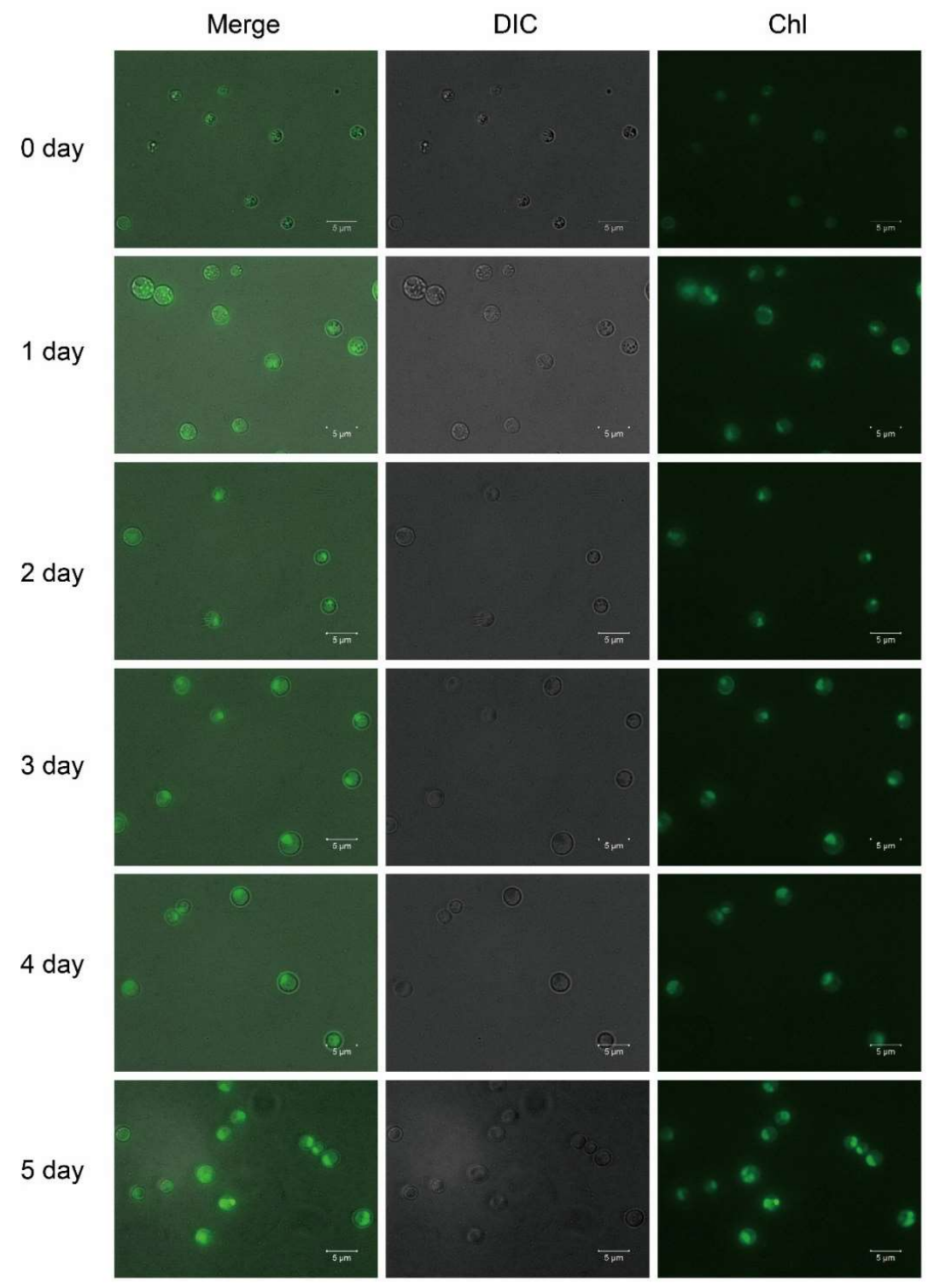

Figure 3. Fluorescence micrographs of A. protothecoides during HA culture. 
The results of high performance liquid chromatography (HPLC) are shown in Figure 4. Compared with the photoautotrophic cells (solid line), the absorption peaks of chlorophyll $a$, chlorophyll $b$, beta-carotene and other pigments disappeared in the heterotrophic condition (dashed line), and only a small absorption peak of lutein was visible. Lutein and chlorophyll therefore showed the same change trend. Moreover, the fact that only a lutein absorption peak was present in the heterotrophic cells is consistent with the measured percentage of lutein in total carotenoids in heterotrophic cells, which almost reached $100 \%$ (Figure 2e).

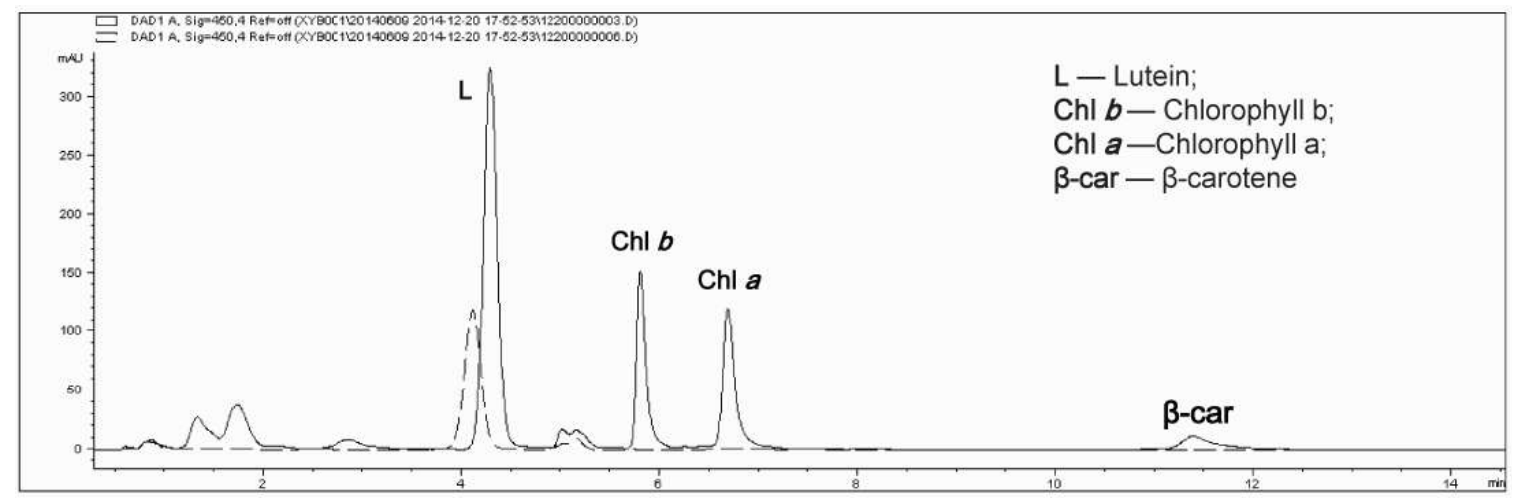

Figure 4. High-performance liquid chromatography (HPLC) chromatogram of carotenoids and chlorophyll in A. protothecoides. The solid line depicts the pigments of photoautotrophic cells and the dashed line depicts the pigments of heterotrophic cells.

In order to characterize the relationship between lutein accumulation and chloroplast regeneration, flow cytometry was used to detect the chlorophyll fluorescence of microalgal cells, and the contents of lutein and total carotenoids in these cells was also analyzed. The statistical analysis showed that there was a positive correlation between chlorophyll fluorescence intensity and the contents of lutein and total carotenoids with all three nitrogen sources (Figure 5). Moreover, the correlation coefficients of the total carotenoids were higher than those of lutein $\left(R^{2}\right.$ urea $=0.9157>0.8723 ; R^{2} \mathrm{NH} 4 \mathrm{Cl}$ $=0.923>0.895 ; R^{2}$ glycine $\left.=0.9414>0.9095\right)$, which indicated that the content of total carotenoids was highly correlated with the intensity of chlorophyll fluorescence. As the major carotenoid, the lutein content was also highly correlated with the intensity of chlorophyll fluorescence. This result is in agreement with the architecture of the PSI-LHCI (Photosystem I-light harvesting complex I) super-complex, comprising the PSI core surrounded by the light-harvesting complex I, combined with a fixed number of chlorophylls and carotenoids ( 155 chlorophylls (Chls) and 35 carotenoids) in higher plants, whereby the proportion of different carotenoids varies according to the environmental conditions [33]. There are two possible ways to increase the lutein content. One way entails changing photosynthesis or chloroplast structure by stress or induced mutations. Another is to increase the proportion of lutein in total carotenoids, which can be achieved by changing the culture conditions or modifying the lutein biosynthesis pathway. 

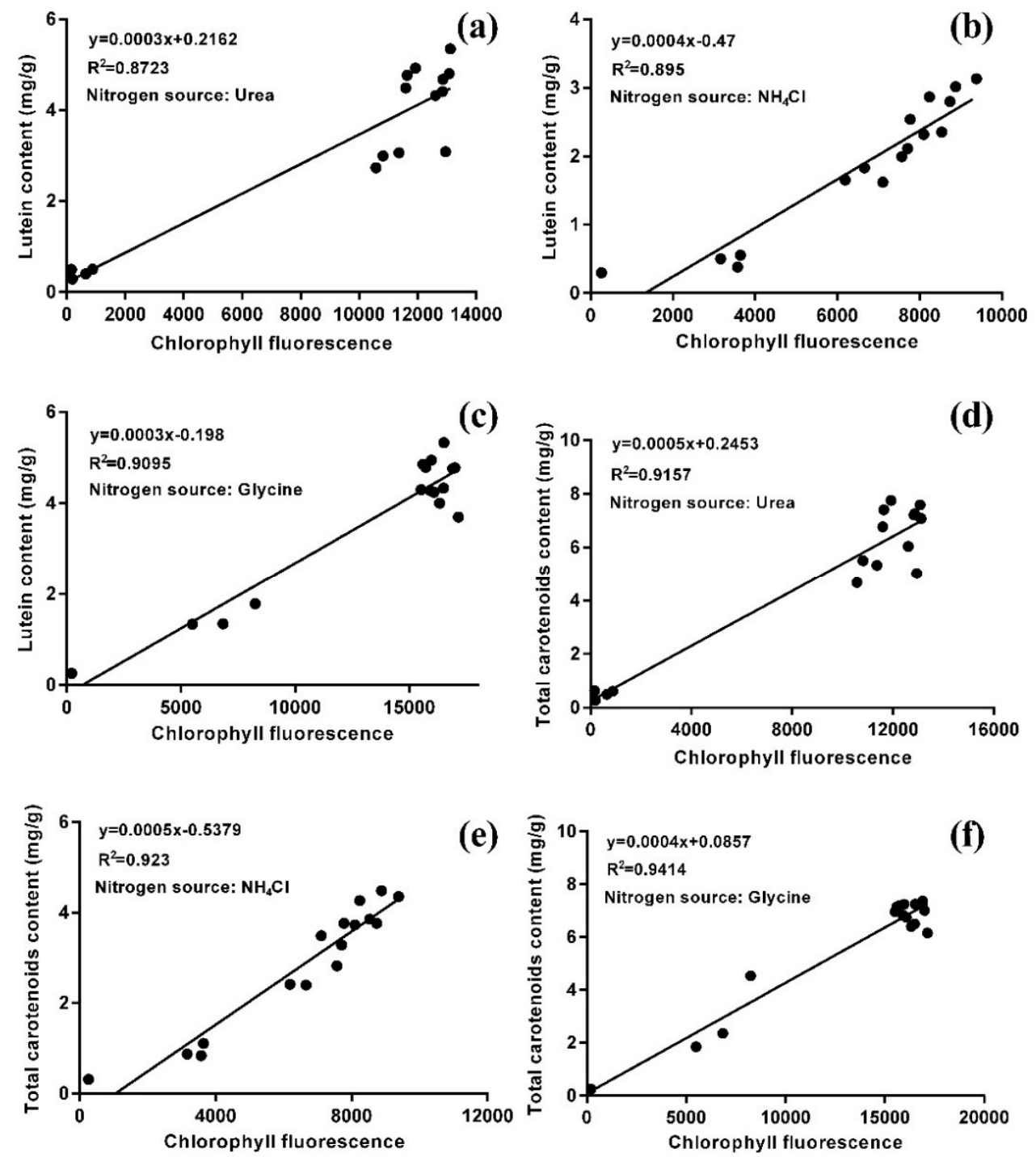

Figure 5. The correlation between lutein content $(\mathbf{a}-\mathbf{c})$ and total carotenoid content $(\mathbf{d}-\mathbf{f})$ with chlorophyll fluorescence of $A$. protothecoides with three nitrogen sources $(\mathrm{N}=0.5 \mathrm{~g} / \mathrm{L})$ in the HA transition culture mode.

\subsection{Comparative Transcriptomic Analysis of the Genes Involved in Lutein Biosynthesis and Photosynthesis}

The activity of the lutein synthesis pathway and photosynthesis metabolic pathway must undergo substantial changes in the process of the disappearance of pigments during the transition from photoautotrophy to heterotrophy. In order to further understand the molecular mechanism of lutein accumulation in $A$. protothecoides, we conducted a comparative transcriptomic analysis of photoautotrophic and heterotrophic cells. Microalgal pigments participate in the photosynthetic system, acting as a light energy absorber [34]. The disappearance of other photosynthetic pigments under heterotrophic conditions along with chloroplast disappearance has been proved. The results of comparative transcriptomic analysis of genes involved in photosynthesis and the lutein synthesis pathway are shown in Table 1. 
Table 1. Comparative transcriptomic analysis of lutein biosynthesis and photosynthesis genes of A. protothecoides in the Photoautotrophic-heterotrophic cultivation ( $\mathrm{AH}$ ) transition culture mode. Positive values indicate upregulation and negative values indicate downregulation.

\begin{tabular}{|c|c|c|c|c|c|c|}
\hline Gene & Enzyme & $\log _{2}(0-3)$ & $\log _{2}(0-6)$ & $\log _{2}(0-12)$ & $\log _{2}(0-24)$ & $\log _{2}(0-72)$ \\
\hline \multirow{2}{*}{$P s b B$} & \multirow{2}{*}{ Photosystem II CP47 chlorophyll apoprotein } & -2.91 & -3.35 & -2.87 & -1.84 & NS \\
\hline & & -0.71 & -2.44 & NS & -0.71 & -2.31 \\
\hline$P s b E$ & Photosystem II cytochrome b559 subunit alpha & -0.21 & -0.01 & -0.24 & -1.42 & NS \\
\hline$P s b H$ & Photosystem II PsbH protein & -1.52 & NS & -0.17 & NS & -0.85 \\
\hline$P s b O$ & Photosystem II oxygen-evolving enhancer protein 1 & -4.64 & -2.98 & -2.79 & -4.90 & -3.92 \\
\hline$P s b P$ & Photosystem II oxygen-evolving enhancer protein 2 & -0.52 & -0.21 & -1.35 & -2.19 & -1.48 \\
\hline$P s b Q$ & Photosystem II oxygen-evolving enhancer protein 3 & -3.93 & -2.52 & -1.51 & -2.07 & -1.62 \\
\hline$P s b R$ & Photosystem II 10kDa protein & -2.27 & -2.42 & -1.60 & -2.90 & -2.70 \\
\hline$P s b S$ & Photosystem II 22kDa protein & -8.43 & -8.01 & -7.43 & -8.14 & -7.73 \\
\hline Psb27 & Photosystem II Psb27 protein & -4.80 & -1.67 & -2.18 & -2.11 & -1.56 \\
\hline$P s b 28$ & Photosystem II 13kDa protein & -0.41 & -1.36 & -3.21 & -2.77 & -2.13 \\
\hline$P s a C$ & Photosystem I subunit VII & NS & NS & NS & NS & NS \\
\hline$P s a D$ & Photosystem I subunit II & -2.32 & -1.88 & -1.81 & -2.15 & -2.45 \\
\hline PsaE & Photosystem I subunit IV & -1.78 & -1.07 & -0.91 & -2.51 & -1.48 \\
\hline PsaF & Photosystem I subunit III & -1.98 & -1.68 & -1.14 & -2.84 & -2.48 \\
\hline$P s a G$ & Photosystem I subunit V & -4.33 & -2.43 & -1.91 & -5.10 & -3.93 \\
\hline PsaK & Photosystem I subunit $X$ & -4.49 & -2.03 & -1.30 & -3.40 & -3.12 \\
\hline PsaL & Photosystem I subunit XI & -2.15 & -1.98 & -1.96 & -4.40 & -4.21 \\
\hline PsaN & Photosystem I subunit PsaN & -4.60 & -3.63 & -3.05 & -4.78 & -3.56 \\
\hline$P s a O$ & Photosystem I subunit PsaO & -2.82 & -1.41 & -0.03 & -1.76 & -1.22 \\
\hline PetC & Cytochrome b6-f complex iron-sulfur subunit & -0.89 & -1.36 & -0.95 & -1.97 & -2.11 \\
\hline $\operatorname{Pet} N$ & Cytochrome b6-f complex subunit 8 & 1.31 & 1.31 & 1.29 & 0.34 & -1.66 \\
\hline PetE & Plastocyanin & -6.16 & -6.73 & -5.35 & -6.14 & -5.77 \\
\hline PetF & Ferredoxin & -1.23 & -1.04 & -1.64 & -2.37 & -3.47 \\
\hline $\mathrm{PetH}$ & Ferredoxin-NADP+ reductase & 0.66 & 0.47 & 0.12 & 0.13 & -1.40 \\
\hline LHCA1 & $\begin{array}{l}\text { Light-harvesting complex I chlorophyll } a / b \text { binding } \\
\text { protein } 1\end{array}$ & -6.22 & -3.93 & -2.76 & -5.95 & -5.77 \\
\hline LHCA3 & $\begin{array}{l}\text { Light-harvesting complex I chlorophyll } a / b \text { binding } \\
\text { protein } 3\end{array}$ & -3.44 & -2.02 & -0.42 & -2.58 & -3.02 \\
\hline \multirow{2}{*}{ LHCA5 } & \multirow{2}{*}{$\begin{array}{l}\text { Light-harvesting complex I chlorophyll } a / b \text { binding } \\
\text { protein } 5\end{array}$} & -6.94 & -6.36 & -6.46 & -8.07 & -4.88 \\
\hline & & -4.49 & -2.98 & -1.29 & -3.14 & -3.58 \\
\hline LHCB3 & $\begin{array}{l}\text { Light-harvesting complex II chlorophyll } a / b \text { binding } \\
\text { protein } 3\end{array}$ & -0.76 & -0.65 & -0.81 & -3.50 & -7.99 \\
\hline LHCB4 & $\begin{array}{l}\text { Light-harvesting complex II chlorophyll } a / b \text { binding } \\
\text { protein } 4\end{array}$ & -2.60 & -1.58 & -1.46 & -3.14 & -2.86 \\
\hline LHCB5 & $\begin{array}{l}\text { Light-harvesting complex II chlorophyll } a / b \text { binding } \\
\text { protein } 5\end{array}$ & -3.33 & -2.81 & -1.06 & -3.07 & -5.82 \\
\hline PDS & 15-cis-phytoene desaturase & -0.71 & -1.01 & -1.13 & -1.60 & -1.19 \\
\hline ZDS & Zeta-carotene desaturase & -1.51 & -1.36 & -1.43 & -2.18 & -1.46 \\
\hline ZEP & Zeaxanthin epoxidase & -5.34 & -5.22 & -1.69 & -3.00 & -1.50 \\
\hline$V D E$ & Violaxanthin de-epoxidase & -6.90 & -7.60 & -5.30 & -5.49 & -3.87 \\
\hline CrtL-e & Lycopene epsilon-cyclase & -1.46 & -0.29 & -0.80 & -1.61 & -1.24 \\
\hline$C r t L-b$ & Lycopene beta-cyclase & -3.05 & -2.00 & -2.03 & -2.46 & -1.46 \\
\hline$C r t R-b$ & Beta-carotene 3-hydroxylase & 1.06 & 0.41 & -0.14 & -1.29 & -0.63 \\
\hline LUT1 & Carotene epsilon-monooxygenase & -2.73 & -0.78 & -0.54 & -1.58 & -1.23 \\
\hline LUT5 & Beta-ring hydroxylase & 2.11 & 1.84 & 2.19 & 0.96 & -0.27 \\
\hline
\end{tabular}


Most of the detected genes in the photosynthesis pathway and antenna proteins were downregulated after $0 \mathrm{~h}$, compared with the photoautotrophic cells. Furthermore, transcriptional expression of PDS, ZDS, ZEP, VDE, CrtL-e, CrtL-b, and LUT1, involved in the lutein synthesis pathway were downregulated after $0 \mathrm{~h}$. All genes involved in photosynthesis and lutein synthesis were downregulated in heterotrophic microalgal cells $(72 \mathrm{~h})$ comparing with photoautotrophic cells. These results corroborated the disappearance of lutein and other carotenoids, accompanied by the degeneration of the photosynthesis system.

It is worth noting that some genes were transiently upregulated during the early period of the AH transition. CrtR-b was upregulated before $12 \mathrm{~h}$, while PetN, PetH, and LUT5 were upregulated before $72 \mathrm{~h}$. PetN and PetH take part in photosynthesis, encoding the cytochrome b6-f complex subunit 8 , and ferredoxin-NADP ${ }^{+}$reductase, respectively. There are two routes leading to lutein from $\alpha$-carotene: $\beta$-ring hydroxylation to zeinoxanthin followed by $\varepsilon$-ring hydroxylation to lutein or $\varepsilon$-ring hydroxylation to $\alpha$-cryptoxanthin, followed by $\beta$-ring hydroxylation to lutein. CrtR-b encodes the $\beta$-ring hydroxylase of $A$. protothecoides. LUT5 (another $\beta$-ring hydroxylase) has been reported to play a key role in carotenoid synthesis by allowing efficient lutein production in Arabidopsis [35]. Two $\beta$-ring hydroxylases were upregulated during the early stages of $\mathrm{AH}$, which might explain why lutein was still the major carotenoid after the disappearance of other pigments. The two genes VDE and ZEP were the most downregulated in lutein synthesis pathway after $0 \mathrm{~h}$. VDE (violaxanthin de-epoxidase) catalyzes the conversion of violaxanthin to zeaxanthin [36], and ZEP (zeaxanthin epoxidase) converts zeaxanthin to violaxanthin via antheraxanthin through two subsequent epoxidation reactions [37]. This means that the biosynthesis of violaxanthin and zeaxanthin was stopped firstly after the $\mathrm{AH}$ transition. Consequently, the lutein proportion among the total carotenoids of heterotrophic cells reached $100 \%$. It has been suggested that activity of zeaxanthin epoxidase (ZEP) and violaxanthin de-epoxidase (VDE) was controlled not only light, but also $\mathrm{pH}$ level [38]. The value of $\mathrm{pH}$ in heterotrophic cultivation was lower than photoautotrophic cultivation in A. protothecoides (data not shown), that means the gene expression of ZEP and VDE possibly regulated by ambient $\mathrm{pH}$. Moreover, carotenoid induction has a correlation with carbon flux and ROS $[39,40]$. The different metabolites accumulation of phototrophic and heterotrophic metabolism decided by different carbon flux was revealed by nonstationary ${ }^{13} \mathrm{C}$ metabolic flux technique in our previous study [41]. The result reveals different metabolites accumulation of phototrophic and heterotrophic metabolism decided by different carbon flux. The regulation of gene expression by carbon flux and ROS signal needs further investigations.

In future studies, the lutein content of $A$. protothecoides can be improved by increasing the lutein proportion in total carotenoids, which can be achieved through the overexpression of LUT5 and CrtR-b, together with a knockdown or knockout of VDE and ZEP.

\section{Materials and Methods}

\subsection{Strain and Culture Conditions}

Auxenochlorella protothecoides (A. protothecoides) strain was obtained from Culture Collection of Algae at the University of Texas (Austin, TX, USA) and screened for high lipid yield in the Algae Bioenergy Laboratory at Tsinghua University (Beijing, China). The cells were maintained in a basal medium containing (per liter): $0.7 \mathrm{~g} \mathrm{KH}_{2} \mathrm{PO}_{4}, 0.3 \mathrm{~g} \mathrm{~K}_{2} \mathrm{HPO}_{4}, 0.3 \mathrm{~g} \mathrm{MgSO} \cdot 7 \cdot \mathrm{H}_{2} \mathrm{O}, 0.3 \mathrm{mg} \mathrm{FeSO} \cdot 7 \mathrm{H}_{2} \mathrm{O}$, $0.01 \mathrm{mg}$ vitamin $\mathrm{B} 1$, and $1 \mathrm{~mL}$ A5 trace mineral solution. The cells were grown in $100 \mathrm{~mL}$ flasks on a shaker set at $220 \mathrm{rpm}$ and $28 \pm 1{ }^{\circ} \mathrm{C}$ for all cultivation modes.

Photoautotrophic cultivation (AC): cells were maintained in a photoautotrophic medium containing basal medium adding $5 \mathrm{~g} / \mathrm{L}$ glycine under illumination of 2000 lux; Heterotrophic cultivation (HC): cells were maintained in a heterotrophic medium containing basal medium adding $30 \mathrm{~g} / \mathrm{L}$ glucose and $0.5 \mathrm{~g} / \mathrm{L}$ glycine under dark condition; Mixotrophic cultivation (MC): cells were maintained in a mixotrophic medium containing basal medium adding $30 \mathrm{~g} / \mathrm{L}$ glucose and $5 \mathrm{~g} / \mathrm{L}$ 
glycine under illumination of 2000 lux; Heterotrophic-photoautotrophic cultivation (HA): cells were cultivated heterotrophically for six days and then transferred into a photoautotrophic medium under illumination of 4000 lux for five days; Heterotrophic-mixotrophic cultivation (HM): cells were cultivated heterotrophically for six days and then transferred into a mixotrophic medium under illumination of 4000 lux for five days; Photoautotrophic-heterotrophic cultivation (AH): cells were cultivated photoautotrophically to log phase and then transferred into a heterotrophic medium under dark conditions.

\subsection{Determination of Biomass, Total Carotenoids and Lutein Content}

Microalgal cells in $1 \mathrm{~mL}$ suspension were harvested by centrifugation and the cell pellets were washed twice with distilled water, dried at $70{ }^{\circ} \mathrm{C}$ until constant weight, and weighed to determine the dry cell weight.

$1 \mathrm{~mL}$ of cell culture was centrifuged at $12,000 \times \mathrm{g}$ for $10 \mathrm{~min}$, and the supernatant was discarded. The pigments were extracted with $3 \mathrm{~mL}$ of acetone: methanol $8: 2(v / v)$ by using a bead beater. Total carotenoids content was determined by using the procedures described by Chan et al. [42]. The optical density of the resulting solution was measured at wavelength of $450 \mathrm{~nm}$ in a spectrophotometer.

A HPLC system loaded with an Agilent 1260 series (Agilent, CA, USA) Chromatographic separation was performed on a Zorbax Extend C18 $(3.5 \mu \mathrm{m}, 2.1 \times 100 \mathrm{~mm}$, Agilent, CA, USA). The carotenoids were eluted through a binary system consisting of Solvent A with methanol and isopropanol in a volumetric ratio of (80:20), while Solvent B was $100 \%$ water. The gradient elution program was as follows: $0-1 \min 85 \% \mathrm{~A}, 1-3 \mathrm{~min} 85 \%$ A to $100 \% \mathrm{~A}, 3-5 \min 100 \% \mathrm{~A}, 5-5.1 \mathrm{~min} 100 \%$ A to $85 \% \mathrm{~A}, 5.1-10 \mathrm{~min} 85 \% \mathrm{~A}$. The flow rate was set at $0.5 \mathrm{~mL} \mathrm{~min}^{-1}$, and the injection volume was $10 \mu \mathrm{L}$. The total run time was $10 \mathrm{~min}$ for each sample. The carotenoids were detected by measuring absorbance at $450 \mathrm{~nm}$. Lutein and $\beta$-carotene were identified using authentic standards (Sigma, St. Louis, MO, USA).

\subsection{RNA Extraction, Library Preparation, Sequencing and Differential Gene Expression Analysis}

A. protothecoides cells were collected at $0,3,6,12,24$, and $72 \mathrm{~h}$ after inoculating the autotrophic cells in the heterotrophic medium. Each sample of $0,3,6,12$, and $24 \mathrm{~h}$ was determined for duplicates. These cells were harvested by centrifugation at $12,000 \times g$ for 5 min and then immediately transferred to liquid nitrogen for preservation before RNA extraction. Total RNA was extracted using TRIzol (Invitrogen, Carlsbad, CA, USA). RNA purification method was same to the previous study [43]. The high-quality RNA samples (OD260/280 $=2-2.2$, OD260 / $230 \geq 2.0$, RIN (RNA integrity number) $\geq 7,28 \mathrm{~S}: 18 \mathrm{~S} \geq 1,>10 \mu \mathrm{g}$ ) were reversed by using a first strand complementary DNA (cDNA) synthesis kit (Fermentas, Burlington, VT, USA) and then applied for the construction of sequencing library. Alignment summary results shown in Table S1. Sequencing data have been deposited at the NCBI sequence read archive under accession number SRA: (http://www.ncbi.nlm.nih.gov/sra/).

A RNA-seq transcriptome library was prepared with $5 \mu \mathrm{g}$ of total RNA according to the manufacturer's instructions of TruSeq ${ }^{\text {TM }}$ RNA sample preparation Kit (Illumina, San Diego, CA, USA). A Paired-end RNA-seq sequencing library was sequenced with the Illumina Hiseq 2000 after quantifification by Agilent Bioanalyzer and a RNA labchip.

Differential gene expression analysis of RNA-seq was done with TopHat 2.0.12 [44] and Cufflinks 2.2.1 [45]. The resulting sequencing data were further normalized to obtain the gene expression RPKM (Reads Per Kilobase per Million mapped reads) value, which allows for the analysis of changes in gene expression between samples. We chose significantly changed genes by selecting those with $\log _{2}>1$ and $p$ value $<0.05$. Functional annotation was carried out using KEGG [46] and Blast2GO 4.15 [47].

\subsection{Fluorescence Microscope Analysis}

A. protothecoides cells were observed under fluorescence microscopy (Zeiss Imager Z2, Vienna, Austria) using chlorophyll $a$ filters for chlorophyll fluorescence. 


\subsection{Flow Cytometry Analysis}

The chlorophyll fluorescence intensity was quantified by using an LSRFortessa cell analyzer (BD Biosciences, San Jose, CA, USA) with a HTS (High throughput screening) automatic sampler. The $640 \mathrm{~nm}$ laser and $670 / 30 \mathrm{~nm}$ filter were used for detection of chlorophyll fluorescence. At least 10000 cells were recorded from each well, among which chlorophyll fluorescence positive cells with appropriate size were gated for calculation using FlowJo (version 7.6.1, TreeStar, Ashland, OR, USA).

\subsection{Statistical Analysis}

The results are expressed as the mean and standard deviation of the three values (mean $\pm \mathrm{SD}$ ). The Student's $t$-test using MS-Excel ${ }^{\mathrm{TM}}$ was conducted for statistical analysis of the experimental data. A $p$ value of less than 0.05 was taken as significant unless otherwise stated. The correlation between total carotenoids content or lutein content $(\mathrm{x}, \mathrm{mg} / \mathrm{L})$ with chlorophyll fluorescence $(\mathrm{y})$ under different nitrogen source were analyzed using linear regression by MS-Excel ${ }^{\mathrm{TM}} . \mathrm{R}^{2}$ was correlation coefficients.

\section{Conclusions}

Auxenochlorella protothecoides was used for lutein production via heterotrophic-photoautotrophic cultivation, a most appropriate cultivation strategy in five culture modes, which resulted in a higher lutein production $(34.13 \mathrm{mg} / \mathrm{L})$ and productivity $(12.36 \mathrm{mg} / \mathrm{L} /$ day) than most reported microalgal production systems. During the photoautotrophic period, lutein accumulation was accompanied by chloroplast regeneration, and there was a positive correlation between chlorophyll fluorescence intensity and lutein content. Glycine was more suitable than urea and $\mathrm{NH}_{4} \mathrm{Cl}$ as nitrogen source for lutein accumulation. Comparative transcriptomic analysis of A. protothecoides genes involved in the lutein biosynthesis pathway and photosystem assembly was conducted for the first time. During the photoautotrophy-heterotrophy transition (AH), two $\beta$-ring hydroxylases (LUT5 and CrtR-b) were upregulated at $0 \mathrm{~h}$, while violaxanthin de-epoxidase (VDE) and zeaxanthin epoxidase (ZEP) were downregulated by the largest margin, which was consistent with the differences of carotenoid accumulation between heterotrophic and photoautotrophic cells.

Supplementary Materials: The following are available online at http:/ /www.mdpi.com/1660-3397/16/8/283/s1, Figure S1: The time course profiles of the lutein content of heterotrophic cells during $24 \mathrm{~h}$ after the transition to fresh medium containing different concentrations of glucose, Table S1: Alignment summary results of the transcriptome analysis.

Author Contributions: Q.W., J.D., and Y.X. conceived and designed the experiments. Y.X. performed the experiments. F.B., X.H., and Q.M. analyzed RNA-seq data. Y.X., Y.L., Q.W., Q.M., X.H., and F.B. analyzed the data and prepared the manuscript.

Funding: This work was supported by the National Science Fund for Distinguished Young Scholars (31725002), by Bureau of International Cooperation, Chinese Academy of Sciences (172644KYSB20170042) and by the Key Research Program of the Chinese Academy of Science (KFZD-SW-215).

Conflicts of Interest: The authors declare no conflicts of interest.

\section{References}

1. Chan, M.C.; Ho, S.H.; Lee, D.J.; Chen, C.Y.; Huang, C.C.; Chang, J.S. Characterization, extraction and purification of lutein produced by an indigenous microalga Scenedesmus obliquus CNW-N. Biochem. Eng. J. 2013, 78, 24-31. [CrossRef]

2. Vidhyavathi, R.; Venkatachalam, L.; Sarada, R.; Ravishankar, G.A. Regulation of carotenoid biosynthetic genes expression and carotenoid accumulation in the green alga. Haematococcus pluvialis under nutrient stress conditions. J. Exp. Bot. 2008, 59, 1409-1418. [CrossRef] [PubMed]

3. Su, Y.X.; Wang, J.X.; Shi, M.L.; Niu, X.F.; Yu, X.H.; Gao, L.J.; Zhang, X.Q.; Chen, L.; Zhang, W.W. Metabolomic and network analysis of astaxanthin-producing Haematococcus pluvialis under various stress conditions. Bioresour. Technol. 2014, 170, 522-529. [CrossRef] [PubMed] 
4. Garcia-Gonzalez, M.; Moreno, J.; Manzano, J.C.; Florencio, F.J.; Guerrero, M.G. Production of Dunaliella salina biomass rich in 9-cis-beta-carotene and lutein in a closed tubular photobioreactor. J. Biotechnol. 2005, 115, 81-90. [CrossRef] [PubMed]

5. Del Campo, J.A.; Moreno, J.; Rodriguez, H.; Vargas, M.A.; Rivas, J.; Guerrero, M.G. Carotenoid content of chlorophycean microalgae: factors determining lutein accumulation in Muriellopsis sp. (Chlorophyta). J. Biotechnol. 2000, 76, 51-59. [CrossRef]

6. Sujak, A.; Gabrielska, J.; Grudzinski, W.; Borc, R.; Mazurek, P.; Gruszecki, W.I. Lutein and zeaxanthin as protectors of lipid membranes against oxidative damage: The structural aspects. Arch. Biochem. Biophys. 1999, 371, 301-307. [CrossRef] [PubMed]

7. Lidebjer, C.; Leanderson, P.; Ernerudh, J.; Jonasson, L. Low plasma levels of oxygenated carotenoids in patients with coronary artery disease. Nutr. Metab. Cardiovasc. Dis. 2007, 17, 448-456. [CrossRef] [PubMed]

8. Moeller, S.M.; Voland, R.; Tinker, L.; Blodi, B.A.; Klein, M.L.; Gehrs, K.M.; Johnson, E.J.; Snodderly, D.M.; Wallace, R.B.; Chappell, R.J.; et al. Associations between age-related nuclear cataract and lutein and zeaxanthin in the diet and serum in the Carotenoids in the Age-Related Eye Disease Study (CAREDS), an ancillary study of the women's health initiative. Arch. Ophthalmol. 2008, 126, 354-364. [CrossRef] [PubMed]

9. Ma, L.; Lin, X.M. Effects of lutein and zeaxanthin on aspects of eye health. J. Sci. Food Agric. 2010, 90, 2-12. [CrossRef] [PubMed]

10. Molnar, P.; Deli, J.; Tanaka, T.; Kann, Y.; Tani, S.; Gyemant, N.; Molnar, J.; Kawase, M. Carotenoids with anti-Helicobacter pylori Activity from Golden Delicious Apple. Phytother. Res. 2010, 24, 644-648. [PubMed]

11. Graziani, G.; Schiavo, S.; Nicolai, M.A.; Buono, S.; Fogliano, V.; Pinto, G.; Pollio, A. Microalgae as human food: chemical and nutritional characteristics of the thermo-acidophilic microalga Galdieria sulphuraria. Food Funct. 2013, 4, 144-152. [CrossRef] [PubMed]

12. Raposo, M.F.D.J.; de Morais, A.M.M.B.; de Morais, R.M.S.C. Carotenoids from Marine Microalgae: A Valuable Natural Source for the Prevention of Chronic Diseases. Mar. Drugs 2015, 13, 5128-5155. [CrossRef] [PubMed]

13. Minhas, A.K.; Hodgson, P.; Barrow, C.J.; Sashidhar, B.; Adholeya, A. The isolation and identification of new microalgal strains producing oil and carotenoid simultaneously with biofuel potential. Bioresour. Technol. 2016, 211, 556-565. [CrossRef] [PubMed]

14. Lin, J.H.; Lee, D.J.; Chang, J.S. Lutein production from biomass: Marigold flowers versus microalgae. Bioresour. Technol. 2015, 184, 421-428. [CrossRef] [PubMed]

15. Xiong, W.; Li, X.F.; Xiang, J.Y.; Wu, Q.Y. High-density fermentation of microalga Chlorella protothecoides in bioreactor for microbio-diesel production. Appl. Microbiol. Biotechnol. 2008, 78, 29-36. [CrossRef] [PubMed]

16. Araya, B.; Gouveia, L.; Nobre, B.; Reis, A.; Chamy, R.; Poirrier, P. Evaluation of the simultaneous production of lutein and lipids using a vertical alveolar panel bioreactor for three Chlorella species. Algal Res. 2014, 6, 218-222. [CrossRef]

17. Neijat, M.; Ojekudo, O.; House, J.D. Effect of flaxseed oil and microalgae DHA on the production performance, fatty acids and total lipids of egg yolk and plasma in laying hens. Prostaglandins Leukot. Essent. Fatty Acids 2016, 115, 77-88. [CrossRef] [PubMed]

18. Brasil, B.D.S.A.F.; de Siqueira, F.G.; Salum, T.F.C.; Zanette, C.M.; Spier, M.R. Microalgae and cyanobacteria as enzyme biofactories. Algal Res. 2017, 25, 76-89. [CrossRef]

19. Sathasivam, R.; Ki, J.S. A Review of the Biological Activities of Microalgal Carotenoids and Their Potential Use in Healthcare and Cosmetic Industries. Mar. Drugs 2018, 16, 26. [CrossRef] [PubMed]

20. Rodolfi, L.; Chini Zittelli, G.; Bassi, N.; Padovani, G.; Biondi, N.; Bonini, G.; Tredici, M.R. Microalgae for Oil: Strain Selection, Induction of Lipid Synthesis and Outdoor Mass Cultivation in a Low-Cost Photobioreactor. Biotechnol. Bioeng. 2009, 102, 100-112. [CrossRef] [PubMed]

21. Lu, Y.; Dai, J.B.; Wu, Q.Y. Photosynthesis-fermentation hybrid system to produce lipid feedstock for algal biofuel. Environ. Technol. 2013, 34, 1869-1876. [CrossRef] [PubMed]

22. Li, M.Y.; Cui, Y.; Gan, Z.B.; Shi, C.L.; Shi, X.M. Isolation and Analysis of the Cppsy Gene and Promoter from Chlorella protothecoides CS-41. Mar. Drugs 2015, 13, 6620-6635. [CrossRef] [PubMed]

23. Chen, C.Y.; Lu, I.C.; Nagarajan, D.; Chang, C.H.; Ng, I.S.; Lee, D.J.; Chang, J.S. A highly efficient two-stage cultivation strategy for lutein production using heterotrophic culture of Chlorella sorokiniana MB-1-M12. Bioresour. Technol. 2018, 253, 141-147. [CrossRef] [PubMed]

24. Chen, C.Y.; Liu, C.C. Optimization of lutein production with a two-stage mixotrophic cultivation system with Chlorella sorokiniana MB-1. Bioresour. Technol. 2018, 262, 74-79. [CrossRef] [PubMed] 
25. Lu, X.; Sun, H.; Zhao, W.Y.; Cheng, K.W.; Chen, F.; Liu, B. A Hetero-Photoautotrophic Two-Stage Cultivation Process for Production of Fucoxanthin by the Marine Diatom Nitzschia laevis. Mar. Drugs 2018, 16, 219. [CrossRef] [PubMed]

26. Salvini, M.; Bernini, A.; Fambrini, M.; Pugliesi, C. cDNA cloning and expression of the phytoene synthase gene in sunflower. J. Plant Physiol. 2005, 162, 479-484. [CrossRef] [PubMed]

27. Steinbrenner, J.; Linden, H. Regulation of two carotenoid biosynthesis genes coding for phytoene synthase and carotenoid hydroxylase during stress-induced astaxanthin formation in the green alga Haematococcus pluvialis. Plant Physiol. 2001, 125, 810-817. [CrossRef] [PubMed]

28. Zhou, L.; Cheng, D.J.; Wang, L.; Gao, J.; Zhao, Q.Y.; Wei, W.; Sun, Y.H. Comparative transcriptomic analysis reveals phenol tolerance mechanism of evolved Chlorella strain. Bioresour. Technol. 2017, 227, 266-272. [CrossRef] [PubMed]

29. Del Campo, J.A.; Rodriguez, H.; Moreno, J.; Vargas, M.A.; Rivas, J.; Guerrero, M.G. Accumulation of astaxanthin and lutein in Chlorella zofingiensis (Chlorophyta). Appl. Microbiol. Biotechnol. 2004, 64, 848-854. [CrossRef] [PubMed]

30. Yan, D.; Dai, J.; Wu, Q. Characterization of an ammonium transporter in the oleaginous alga Chlorella protothecoides. Appl. Microbiol. Biotechnol. 2013, 97, 919-928. [CrossRef] [PubMed]

31. Hu, J.; Nagarajan, D.; Zhang, Q.; Chang, J.S.; Lee, D.J. Heterotrophic cultivation of microalgae for pigment production: A review. Biotechnol. Adv. 2018, 36, 54-67. [CrossRef] [PubMed]

32. Zhao, L.; Dai, J.; Wu, Q. Autophagy-like processes are involved in lipid droplet degradation in Auxenochlorella protothecoides during the heterotrophy-autotrophy transition. Front Plant Sci. 2014, 5, 400. [CrossRef] [PubMed]

33. Qin, X.; Suga, M.; Kuang, T.; Shen, J.R. Photosynthesis. Structural basis for energy transfer pathways in the plant PSI-LHCI supercomplex. Science 2015, 348, 989-995. [CrossRef] [PubMed]

34. Markou, G.; Nerantzis, E. Microalgae for high-value compounds and biofuels production: A review with focus on cultivation under stress conditions. Biotechnol. Adv. 2013, 31, 1532-1542. [CrossRef] [PubMed]

35. Kim, J.; DellaPenna, D. Defining the primary route for lutein synthesis in plants: The role of Arabidopsis carotenoid beta-ring hydroxylase CYP97A3. Proc. Natl. Acad. Sci. USA 2006, 103, 3474-3479. [CrossRef] [PubMed]

36. Hallin, E.I.; Guo, K.; Akerlund, H.E. Violaxanthin de-epoxidase disulphides and their role in activity and thermal stability. Photosynth. Res. 2015, 124, 191-198. [CrossRef] [PubMed]

37. Coesel, S.; Obornik, M.; Varela, J.; Falciatore, A.; Bowler, C. Evolutionary Origins and Functions of the Carotenoid Biosynthetic Pathway in Marine Diatoms. PLoS ONE 2008, 3, e2896. [CrossRef] [PubMed]

38. Jahns, P.; Latowski, D.; Strzalka, K. Mechanism and regulation of the violaxanthin cycle: The role of antenna proteins and membrane lipids. Biochim. Biophys. Acta 2009, 1787, 3-14. [CrossRef] [PubMed]

39. Sun, T.; Yuan, H.; Cao, H.; Yazdani, M.; Tadmor, Y.; Li, L. Carotenoid Metabolism in Plants: The Role of Plastids. Mol. Plant 2018, 11, 58-74. [CrossRef] [PubMed]

40. Havaux, M. Carotenoid oxidation products as stress signals in plants. Plant J. 2014, 79, 597-606. [CrossRef] [PubMed]

41. Wu, C.; Xiong, W.; Dai, J.; Wu, Q. Genome-Based Metabolic Mapping and 13C Flux Analysis Reveal Systematic Properties of an Oleaginous Microalga Chlorella protothecoides. Plant Physiol. 2015, 167, 586-599. [CrossRef] [PubMed]

42. Taylor, K.L.; Brackenridge, A.E.; Vivier, M.A.; Oberholster, A. High-performance liquid chromatography profiling of the major carotenoids in Arabidopsis thaliana leaf tissue. J. Chromatogr. A 2006, 1121, 83-91. [CrossRef] [PubMed]

43. He, X.; Dai, J.; Wu, Q. Identification of Sporopollenin as the Outer Layer of Cell Wall in Microalga Chlorella protothecoides. Front. Microbiol. 2016, 7, 1047. [CrossRef] [PubMed]

44. Kim, D.; Pertea, G.; Trapnell, C.; Pimentel, H.; Kelley, R.; Salzberg, S.L. TopHat2: accurate alignment of transcriptomes in the presence of insertions, deletions and gene fusions. Genome Biol. 2013, 14, R36. [CrossRef] [PubMed]

45. Trapnell, C.; Roberts, A.; Goff, L.; Pertea, G.; Kim, D.; Kelley, D.R.; Pimentel, H.; Salzberg, S.L.; Rinn, J.L.; Pachter, L. Differential gene and transcript expression analysis of RNA-seq experiments with TopHat and Cufflinks. Nat. Protoc. 2012, 7, 562-578. [CrossRef] [PubMed] 
46. Kanehisa, M.; Goto, S. KEGG: Kyoto Encyclopedia of Genes and Genomes. Nucleic Acids Res. 2000, 28, 27-30. [CrossRef] [PubMed]

47. Conesa, A.; Gotz, S.; Garcia-Gomez, J.M.; Terol, J.; Talon, M.; Robles, M. Blast2GO: A universal tool for annotation, visualization and analysis in functional genomics research. Bioinformatics 2005, 21, 3674-3676. [CrossRef] [PubMed]

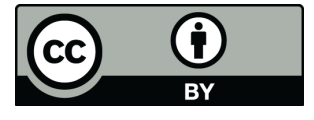

(C) 2018 by the authors. Licensee MDPI, Basel, Switzerland. This article is an open access article distributed under the terms and conditions of the Creative Commons Attribution (CC BY) license (http:/ / creativecommons.org/licenses/by/4.0/). 